\title{
Genome-wide identification and expression analysis of auxin response factor gene family in Medicago truncatula
}

\author{
Chenjia Shen ${ }^{1+}$, Runqing Yue ${ }^{2+}$, Tao Sun ${ }^{1}$, Lei Zhang ${ }^{3}$, Luqin $X u^{1}$, Shuanggui Tie ${ }^{2}$, Huizhong Wang ${ }^{1 *}$ \\ and Yanjun Yang ${ }^{*}$
}

\author{
${ }^{1}$ College of Life and Environmental Sciences, Hangzhou Normal University, Hangzhou, China \\ 2 Henan Academy of Agricultural Sciences, Zhengzhou, China \\ ${ }^{3}$ Department of Plant Pathology, Washington State University, Pullman, WA, USA
}

Edited by:

Jeff H. Chang, Oregon State

University, USA

Reviewed by:

Serena Varotto, University of

Padova, Italy

Laurent Laplaze, Institut de

Recherche pour le Développement.

France

*Correspondence:

Huizhong Wang and Yanjun Yang,

College of Life and Environmental

Sciences, Hangzhou Normal

University, 16 Xuelin Street,

Hangzhou 310036, China

e-mail:whz62@163.com;

yjyang@hznu.edu.cn

tThese authors have contributed equally to this work.
Auxin response factors (ARFs) bind specifically to auxin response elements (AuxREs) in the promoters of down-stream target genes and play roles in plant responses to diverse environmental factors. Using the latest updated Medicago truncatula reference genome sequence, a comprehensive characterization and analysis of 24 MtARF ( $M$. truncatula $A R F)$ genes were performed. To uncover the basic information and functions of MtARF genes during symbiosis, we analyzed the expression patterns of MtARF genes during the early phase of Sinorhizobium meliloti infection. The systematic analysis indicated that changes in MtARF gene expression occur during these early stages of infection, suggesting a functional role in symbiosis. Furthermore, the roles of MtARF-mediated auxin signaling in symbiosis were tested in the infection resistant mutant (dmi3). The expression responses of MtARFs to $S$. meliloti infection were attenuated in the mutant compared to wild-type A17. In summary, our results show that changes in MtARF gene expression occur during the response to $S$. meliloti infection, suggesting that members of this family may have important roles in the symbiotic interaction.

Keywords: auxin response factor (ARF), auxin, auxin signaling, nodule formation, Sinorhizobium meliloti infection

\section{INTRODUCTION}

The phytohormone auxin is involved in regulating many aspects of plant growth and development, including root system architecture re-establishment under nutrient stress and responses to environmental stimuli. The transcription of numerous genes are altered rapidly and specifically by auxin treatment (Chung et al., 2011; Molesini et al., 2014) and the Auxin Response Factor (ARF) gene family plays a vital role in response to indole-3-acetic acid (IAA) by regulating expression of down-stream target genes. Many early auxin-responsive gene promoters contain one or several copies of a conserved motif (TGTCTC) or its variants, which is called the auxin-responsive element (AuxRE) (Guilfoyle and Hagen, 2007). Components of the auxin signaling pathway have already been revealed in recent years (Hayashi, 2012). Recognition of the auxin/indole-3-acetic acid (Aux/IAA) proteins by the auxin transport inhibitor response 1 (TIR1), which is located at the top of SCF ${ }^{\text {TIR1/AFB }}$ ubiquitin ligase, accelerates Aux/IAA protein degradation by the $26 \mathrm{~S}$ proteasome. Therefore, ARFs, which are inhibited by Aux/IAA, are released and began to modulate the expression of their target genes (Tan et al., 2007).

Classical genetic approaches have been used to functionally characterize the $A R F$ genes during plant growth, development, and responses to environmental stimuli. In Arabidopsis, the ARF3 loss-of-function mutation caused a defect in gynoecium patterning (Nishimura et al., 2005); the arf5 mutant showed abnormal formation of vascular strands and the embryo axis (Hardtke and Berleth, 1998); the ARF7 loss-of-function mutation impaired hypocotyl response to blue light and auxin stimuli (Harper et al., 2000); the ARF8 loss-of-function mutation affected hypocotyl elongation and auxin homeostasis (Goetz et al., 2006) and a double mutant, arf7/arf19, affected auxin mediated lateral root development (Narise et al., 2010). Transgenic rice expressing an antisense of OsARF1 were stunted in growth, sterile, and had low vigor, curled leaves, as well as altered organ size, relative to wildtype plants (Aya et al., 2014). OsARF12 has been shown to play a role in iron homeostasis (Qi et al., 2012) and OsARF16 facilitated the efficient utilization of phosphate in rice plant (Shen et al., 2013).

Many legume species interact with nitrogen-fixing bacteria (rhizobia) to form symbioses (van Noorden et al., 2007). Numerous genes are specifically involved in the formation of nodules, which are the symbiotic legume organs that house nitrogen-fixing bacteria during host plant and symbiotic rhizobia interactions (Nallu et al., 2013). Previous reports indicated that there was a positive correlation between auxin signaling and nodule formation in Medicago truncatula (Roudier et al., 2003; Kondorosi et al., 2005). Auxin, which plays a crucial role in plant control of cell division and elongation, is likely to be an important nodulation regulator (Blilou et al., 2005). Auxin signaling is initiated through activation of transcriptional response mediated by the AUX/IAA and ARF families of transcriptional regulators (Chapman et al., 2012). In Arabidopsis, ARF2 was reported to be involved in the controlling of differential cell division and elongation, which was an important process of nodulation (Li et al., 
2004). Furthermore, inhibition of auxin polar transport at the nodule site is a prerequisite for nodule initiation in indeterminate legumes (Wasson et al., 2006).

As a model indeterminate legume, $M$. truncatula has been used to reveal how auxin signaling participates in nodule initiation. A high concentration of auxin reduced the number of nodules in M. truncatula and a low concentration of auxin increased nodule numbers (van Noorden et al., 2006). Previous studies showed that in $M$. truncatula the expressions of the auxin responsive reporter genes were localized in the inner and outer cortical cells when they were dividing, which indicated that regulation of mitosis during nodulation was the main role of auxin (Kondorosi et al., 2005). The control of auto-regulation of nodulation (AON) depends on long-distance auxin transport from the shoots to roots (van Noorden et al., 2006). The application of auxin polar transport inhibitors, such as N-(1-naphthyl) phthalamic acid (NPA) and 2, 3, 5-triiodobenzoicacid (TIBA) induced the formation of pseudo-nodules in M. truncatula (Rightmyer and Long, 2011). A close relationship has been found between the root nodule formation and auxin transport inhibition (Wasson et al., 2006). However, the underlying mechanism linking auxin signaling and nodule formation during the early phase of Sinorhizobium meliloti infection of M. truncatula remains largely unknown.

As an important segment of the auxin signaling pathway, ARFs are encoded by a multigene family present in many different plant species. There are 23 members in Arabidopsis, 22 members in tomato (Solanum lycopersicon), 31 members in maize (Zea mays L.), 15 members in cucumber (Cucumis sativus), 39 members in poplar (Populus trichocarpa), 25 members in rice (Oryza sativa L.), and 51 members in soybean (Glycine max L.) (Guilfoyle and Hagen, 2007; Kalluri et al., 2007; Liu et al., 2007; Wang et al., 2007, 2012; Shen et al., 2013; Zouine et al., 2014). This study provides detailed information on the gene structures, chromosomal locations, sequence homologies, and expression patterns of $24 A R F$ genes in $M$. truncatula. We provide new information about the complexity of $M$. truncatula ARF expression control during the early phase of $S$. meliloti infection. The distinct spatio-temporal expression patterns for $M$. truncatula ARF genes and their differential responses to rhizobial symbiosis provide the foundation for a more comprehensive functional characterization of these transcriptional mediators and their involvement in the formation of root nodules.

\section{MATERIALS AND METHODS PLANT MATERIAL, GROWTH CONDITIONS, AND HORMONE TREATMENT}

M. truncatula $\mathrm{cv}$ Jemalong plants (wild-type A17) were scarified with sand paper, surface sterilized with $6.25 \%$ (v/v) hypochlorite for $8 \mathrm{~min}$ and washed five times with sterile water, and germinated on plates containing buffered nodulation medium BNM (Engstrom et al., 2002) with $0.8 \%$ agar and $1 \mu \mathrm{M}$ imidazoline betaine (AIB) in the dark over night at $30^{\circ} \mathrm{C}$. Seedlings were transferred to large Petri dishes containing a nitrogen-free BNM medium, five seedlings per plate. Plates were kept vertical and black paper was used to cover the sides of each plate, and an aluminum foil spacer was laid between the medium and Petri dish to help air exchange. Seedlings were incubated in a growth chamber at a constant $22^{\circ} \mathrm{C}$ during a $16 \mathrm{~h}$ day and $8 \mathrm{~h}$ night with a photon flux density of $100 \mu \mathrm{molm}^{-2} \mathrm{~s}^{-1}$. For the infection treatment on M. truncatula seedlings, 14-day-old seedlings ( 10 seedlings) were soaked in liquid BNM medium with or without (mock treatment) $10 \mu \mathrm{M}$ IAA, then the roots and shoots of $M$. truncatula seedlings were collected for RNA isolation. For infection experiment, the seedlings were soaked in liquid BNM medium under different treatments. These treatments were $-\mathrm{Sin} /-\mathrm{NOA},+\mathrm{Sin} /-\mathrm{NOA},-\mathrm{Sin} /+\mathrm{NOA}$, and +Sin/+NOA. The treatment $-\mathrm{Sin} /-\mathrm{NOA}$ was used as mock treatment $(\mathrm{Sin}=$ S. meliloti infection; NOA $=10 \mu \mathrm{M} 1-\mathrm{NOA}$ treatment; -Sin/NOA: mock treatment; -Sin/+NOA: NOA treatment positive control). The experiment was repeated for five times with similar results.

\section{IDENTIFICATION OF ARF GENES IN M. TRUNCATULA}

Comprehensive identification of $M$. truncatula ARF gene family members was achieved using Arabidopsis ARF proteins previously reported as phytozome BLAST queries of the M. truncatula genome database (http://www.phytozome.net/). The e-value acceptable in the Blast analysis for ARF member identification was " $10^{-3}$ ". The hidden Markov model (HMM) profiles of the ARF gene family [Pfam 02309: AUX/IAA family; Pfam 06507: ARF (AUX_RESP); Pfam 02362: B3 DNA binding domain (B3)] were employed to identify the $A R F$ genes from the M. truncatula genome. These profiles were used to search the complete proteome of M. truncatula available in phytozome (http:// www.phytozome.net/). All the obtained sequences were sorted as unique sequences for further studies. B3, AUX_RESP, and Aux/IAA domain were analyzed using InterProScan Sequence Search (http://www.ebi.ac.uk/Tools/pfa/iprscan/). The miRNA locations on the MtARFs were searched using PMRD data (http:// bioinformatics.cau.edu.cn/PMRD/). Linear display of synteny blocks were retrieved from the SyMAP database (http://www. symapdb.org/projects/fabaceae/).

\section{PHYLOGENETIC TREE BUILDING AND PREDICTION OF AMINO ACID COMPOSITION}

Multiple sequence alignments were performed on the MtARF nucleotide sequences using ClustalW with the default parameters. The gap open penalty parameter is 15 , gap extension penalty parameter is 6.66 , and the weight matrix selected is "IUB" for DNA. The alignments were subsequently visualized using GeneDoc (http://www.nrbsc.org/gfx/genedoc/) as presented in Figure S1. Phylogenetic tree was constructed with aligned $24 M t A R F$ nucleotide sequences, 23 AtARF nucleotide sequences, and $51 G m A R F$ nucleotide sequences using MEGA5.1 (http://www.megasoftware.net/mega.php) employing the neighbor-joining (NJ) method. Bootstrap values were calculated from 1000 iterations. The constructed tree file was visualized by TreeView1.6 (http://taxonomy.zoology.gla.ac.uk/rod/ treeview.html). The software MEGA 5.1 was used for calculation of amino acid composition of the MR domain in MtARFs.

\section{INTRON/EXON STRUCTURE, GENOME DISTRIBUTION, AND MOTIF PREDICTION}

The DNA and cDNA sequences corresponding to each predicted gene from the $M$. truncatula genome and the information 
of MtARFs intron distribution pattern were obtained from the http://www.phytozome.net/cgi-bin/gbrowse/medicago. To obtain the gene location, we drew a map of the distribution of MtARF genes throughout the M. truncatula genome. Comparisons to the Pfam database were used to identify motifs present in the MtARF protein sequences.

\section{RNA ISOLATION AND qRT-PCR}

Total RNA from the cotyledons, leaves, shoots, roots, and flowers was extracted using a Plant RNeasy Mini kit (Qiagen, Hilden, Germany) according to the manufacturer's instructions. Then DNase I treatment was used to remove genomic DNA contamination from total RNA. The cDNA was synthetized using ReverAid First Strand cDNA Synthesis Kit (Thermo Scientific \#1622). The primer sequences are listed in Table S1. Briefly, $1 \mu$ l of a $1 / 10$ dilution of cDNA in double distilled water was add to $5 \mu \mathrm{l}$ of $2 \times$ UltraSYBR, $100 \mathrm{nM}$ of each primer and water was then added to final volume $10 \mu \mathrm{l}$. The procedures for PCR were as follows: $95^{\circ} \mathrm{C}$ for $10 \mathrm{~min} ; 40$ cycles of $95^{\circ} \mathrm{C}$ for $15 \mathrm{~s}, 60^{\circ} \mathrm{C}$ for $60 \mathrm{~s}$. (All reactions were run in triplicate.) Relative fold differences were calculated based on the comparative Ct method using Mt-Actin (MTR_2g008050) as an internal standard. Heat map representation was performed using the normalized $\left(2^{-\Delta \Delta C t}\right)$ value with ClustalW software and Treeview to visualize the data. The expression folds were used by Treeview to visualize as heat map. In our experiment, a specific fold change value $(2 \times)$ in the expression levels is used to clarify the statistical analysis of significant differences among mock and the treatments. All the expression analysis was carried out for five biological repeats and the values shown in figures represented the average values of these five repeats. Three technical replicates were contained in each biological repeat.

\section{BACTERIAL STRAINS AND RHIZOBIA INFECTION}

The rhizobia strain used for inoculating the roots of seedlings was S. meliloti strain 1021 (from ATCC data base, ATCC $^{\circledR}$ Number: 51124), a streptomycin-resistant derivative of wild-type. S. meliloti was grown overnight at $28^{\circ} \mathrm{C}$ in liquid LBMC medium ( $10 \mathrm{~g} / \mathrm{L}$ tryptone, $5 \mathrm{~g} / \mathrm{L}$ yeast extract, $10 \mathrm{~g} / \mathrm{L} \mathrm{NaCl}, 2.6 \mathrm{mM} \mathrm{MgSO}_{4}$, $2.6 \mathrm{mM} \mathrm{CaCl}_{2}$ ) supplemented with $200 \mu \mathrm{g} / \mathrm{ml}$ streptomycin, then collected by centrifugation, and suspended in $10 \mathrm{mM} \mathrm{MgSO}_{4}$. The bacterial suspension was diluted with liquid BNM medium to $\mathrm{OD}_{600}=0.1$. For plant inoculation, each seedling was placed in a single $50 \mathrm{ml}$ tube containing the nitrogen-free nutrient solution plus perlite and treated with BNM medium diluted bacteria. For control (mock-inoculated), the seedlings were treated with sterilized BNM medium containing $10 \mathrm{mM} \mathrm{MgSO}_{4}$. Different sets of plants were grown and used for the various analyses.

\section{RESULTS}

\section{GENOME-WIDE IDENTIFICATION OF ARF GENES IN M. TRUNCATULA}

After gene structure and protein domain analysis, $24 A R F$ genes were identified in $M$. truncatula. These genes were named according to gene locations on the chromosomes (from Chr. 1 to Chr. 8). All the information on these $24 M t A R F$ genes, such as gene names, locus IDs, ORF lengths, numbers of introns, locations on chromosomes, and basic information about deduced polypeptides are listed in Table S2. The sizes of the deduced MtARF proteins varied markedly from 323 amino acids (MtARF4) to 1252 amino acids (MtARF22). The corresponding molecular masses varied from 36.92 to $141.13 \mathrm{kDa}$ and the predicted isoelectric points varied from 5.08 (MtARF16) to 8.48 (MtARF22).

\section{CHROMOSOMAL DISTRIBUTION AND EXPANSION ANALYSIS OF MtARF GENES}

$M T A R F$ gene locations were mapped on chromosome sequences in order to gain an insight into the organization of MtARF genes, which may be involved in auxin signaling. Based on the available $M$. truncatula genome assembly sequence, the M. truncatula $A R F$ gene mapping revealed that $24 M t A R F$ genes were distributed among seven chromosomes (out of a total of eight chromosomes in the M. truncatula genome). A total of $24 M t A R F$ genes were present on all chromosomes, except chromosome 6. Among these 24 MtARF genes, seven (29.2\%) genes were located on chromosome 2 and eight (33.3\%) genes were located on chromosome 5. Chromosomes 1 and 7 contained only one MtARF gene each; chromosomes 3 and 8 each contained two MtARF genes and chromosome 4 had three MtARF genes (Figure 1A).

Many studies have found that gene divergence and duplication events are the primary contributors to evolutionary momentum (Bowers et al., 2003). Gene duplication events, which consist of tandem and segmental duplications, were identified and plotted on to chromosomes in an attempt to explain the expansion of $M$. truncatula $A R F$ family genes during the evolutionary process. All gene sister pairs that were classified into tandem duplication or segmental duplication groups were shown in Figures 1B,C. Seven gene sister pairs were identified. These were four pairs of segmental duplicates: MtARF1/MtARF8, MtARF2/MtARF11, $M t A R F 9 / M t A R F 20$, and MtARF13/MtARF23, which are linked by the blue arrows, and three tandem duplicates: MtARF3/MtARF4, MtARF14/MtARF15, and MtARF16-19, which are delimited by the red arrows.

\section{ANALYSIS OF AMINO ACID COMPOSITION AND CLASSIFICATION OF MtARFs}

The domain positions in the 24 MtARF proteins are shown in Table S3 and the amino acid composition of the Middle Regions (MRs) is shown in Figure S2 (the data was listed in Table S4). The 24 MtARFs were categorized into three subgroups, based on their MR amino acid composition and the presence or absence of Carboxy-Terminal Domains (CTDs). These are: (1) ARF proteins with a DNA Binding Domain (DBD), activator MR and a CTD; (2) ARF protein with a DBD, repressor MR and a CTD; and (3) ARF proteins with a DBD, repressor MR, but no CTD (Figure S2B). The M. truncatula ARF family encodes five putative transcriptional activators: MtARF6, 9, 13, 20, and 24 [MR enriched with glutamine $(\mathrm{Q})$, serine $(\mathrm{S})$, and leucine $(\mathrm{L})]$ and five putative transcriptional repressors: MtARF2, 7, 8, 22, and 23 [MR enriched with S, L, proline $(\mathrm{P})$ and glycine $(\mathrm{G})$ ]. Fourteen MtARF proteins are putative transcriptional repressors that do not contain a CTD: MtARF1, 3, 4, 5, 10, 12, 14, 15, 16, 17, 18, 19 , and 21. 


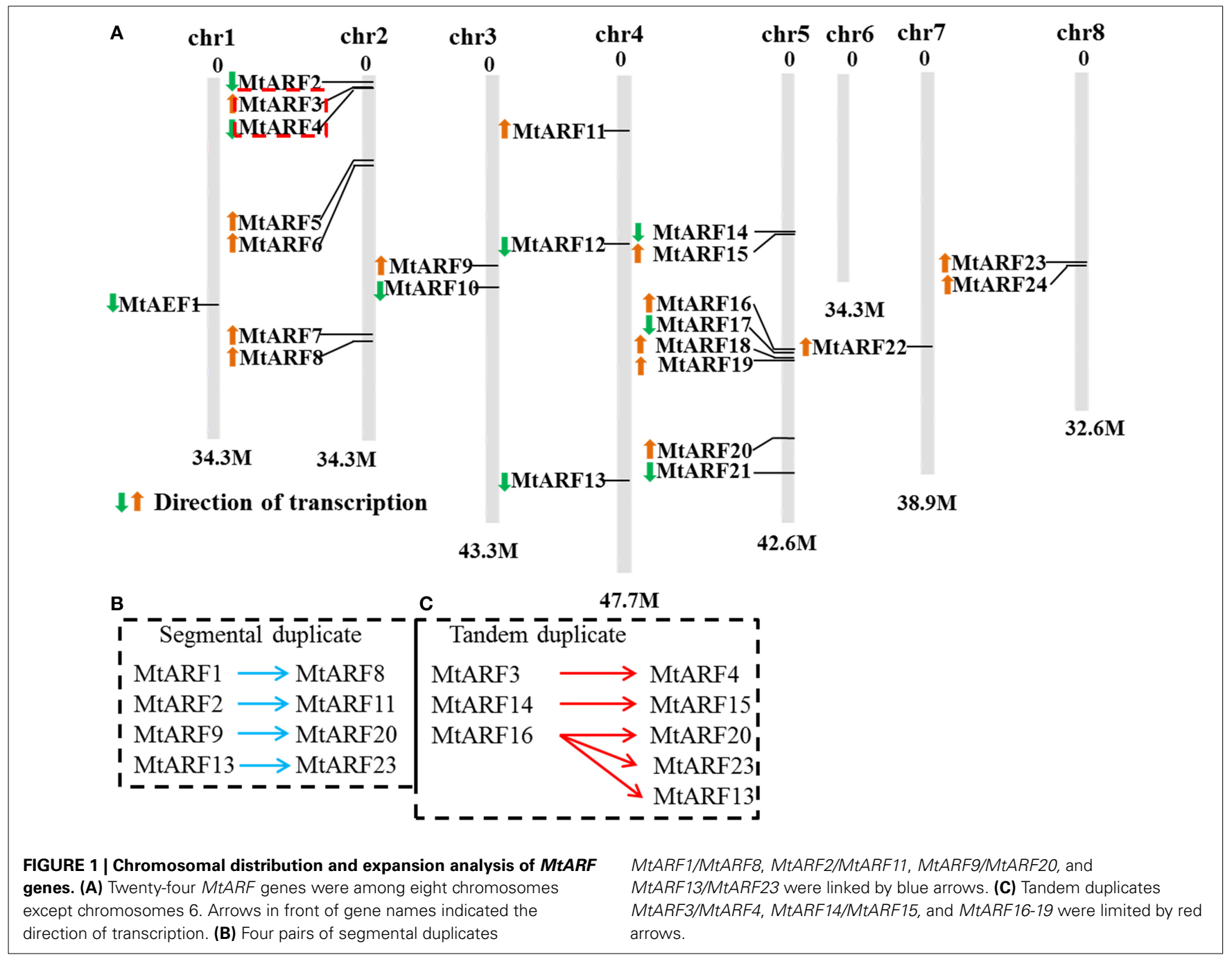

ANALYSIS OF PHYLOGENETIC RELATIONSHIPS AMONG ARF PROTEINS

A phylogenetic tree was constructed to explore the phylogenetic relationships of $A R F$ genes among different species. The ARF genes in the model plant Arabidopsis and leguminous plant soybean were used for phylogenetic tree construction (Figure 2). The phylogenetic distribution revealed that $A R F$ genes can be grouped into eight major subclasses (from I to VIII). All the MtARFs that were predicted to function as transcriptional activators and contained a Q-rich MR domain belonged to subclasses IV and V (MtARF6, 9, 13, 20, and 24) and MtARFs that were predicted to function as transcriptional repressors belonged to subclass I (MtARF2, 7, 8, 22, and 23). Most of the MtARF proteins containing the $\mathrm{B} 3$ DNA binding domain (DBD) and the AUX/IAA family domain (CTD) were found in subclass I, II, IV, and V (MtARF1, 5, and 12 were belonged into subclass II. All the MtARFs in subclass VI, VII, and VIII did not contain an AUX/IAA family domain (CTD). The MtARF genes from subclass I, II and IV-VII were very closely related to the $A R F$ genes from soybean and Arabidopsis. However, the MtARF genes belonged to subclass VIII, were not closely related to any soybean or Arabidopsis ARF genes indicating a diverging trend in the evolution of ARF family members across different plant species.

\section{EXPRESSION PATTERNS FOR MtARF GENES IN DIFFERENT M. TRUNCATULA TISSUES}

The spatial specificity expression pattern of individual members of the MtARF family was examined in the different $M$. truncatula tissues using qRT-PCR. These were the roots, stems, cotyledons and leaves of 2-week old seedlings and the flowers from 2-month old plants. Transcripts of the $24 M t A R F$ genes could be detected in the different tissues (Figure 3). Most MtARF gene expressions were ubiquitously in all tissues, which suggested they have a putative function in many aspects of plant growth and development, including root system regulation, shoot initiation and growth, apical dominance, and embryonic development.

\section{PREDICTION OF THE microRNA PUTATIVE TARGET SITES OF MtARF GENES}

In Arabidopsis, the expression levels of ARF6 and ARF8 are regulated by microRNA167 (Yang et al., 2006) and ARF10, 16, and 17 were targeted by microRNA160 (Liu et al., 2007). To 


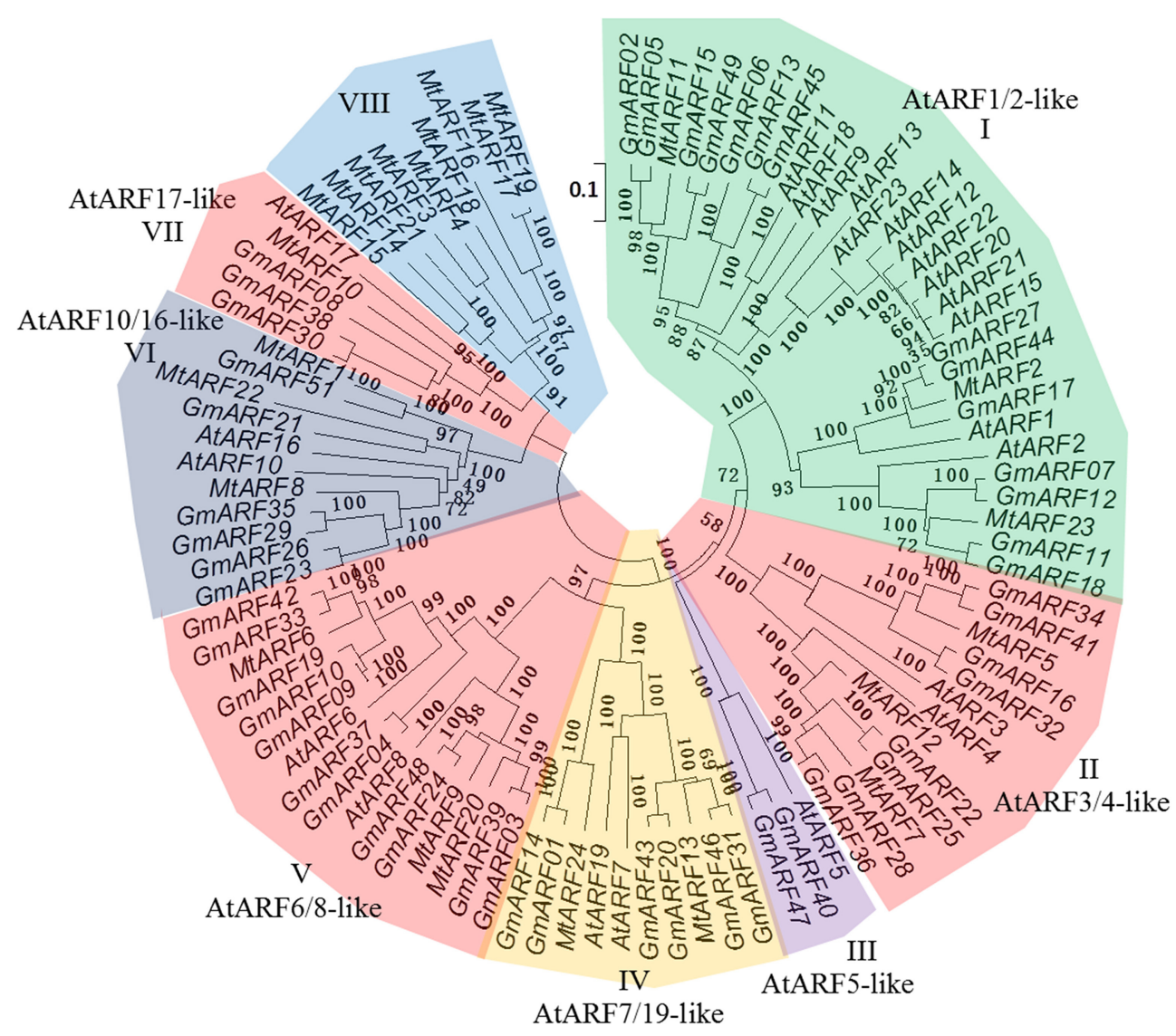

FIGURE 2 | Analysis of phylogenetic relationship of ARF genes in M. truncatula, model plant Arabidopsis and leguminous plant soybean. Bootstrap values are presented for all branches. Twenty-four MtARF genes,
23 AtARF genes, and $51 \mathrm{GmARF}$ genes were classified into eight subclasses (from I to VIII). Scale bar 0.1 denoted 0.1 nucleotide substitution per site. The $A R F$ genes were color coded according to their classes. explore whether there was potential regulation of MtARF genes by microRNA, we studied the ARF protein phylogenetic relationships between Arabidopsis and M. truncatula. A phylogenetic tree was constructed using ARF family members from Arabidopsis and M. truncatula. The results showed that MtARF1 and MtARF10 were highly homologous with AtARF16 and AtARF17, and $M t A R F 6$ and MtARF9 were highly homologous with AtARF6 and AtARF8, respectively.

Our results suggest that five precursors (mtr-miR160, $160 b, 160 c, 160 d$, and $160 e$ ) in the M. truncatula genome were needed to produce the mature mtr-miRNA160 sequence (UGCCUGGCUCCCUGUAUGCCA), but only one precursor (mtr-miRNA167) was needed to produce the mature mtr-miRNA167 sequence (UGAAGCUGCCAGCAUGAUCUA). Sequence analysis of $A R F s$ in $M$. truncatula implied that the 1344-1364 bp region on MtARF1 and the 1314-1330 bp region on MtARF10 may be the target sites of miRNA160 and the 24572477 bp region on $M t A R F 6$ and the 2301-2321 bp region on $M t A R F 9$ may be the target sites of miRNA167 (Figure 4).

\section{EXPRESSION RESPONSES OF MtARF GENES TO AUXIN TREATMENT IN DIFFERENT TISSUES}

As a key component of the auxin signaling pathway, responsiveness to auxin is one of the important features of $A R F$ genes. In our study, the transcript levels of $24 M t A R F$ genes were assessed by qRT-PCR in the shoots and roots of 2-week old seedlings after treatment with $10 \mu \mathrm{M}$ IAA for $1 \mathrm{~h}$. Most of $M T A R F$ genes were found to be auxin responsive after IAA treatment, with $14 M t A R F$ genes showing up-regulation, whereas only MtARF4, MtARF15, MtARF18, and MtARF21 displayed down-regulation in the shoots. MtARF7, 9, 13, 17, and 24 showed almost no response to IAA treatment in the shoots. In the roots, the expression levels of $10 M t A R F$ genes were upregulated and $14 M t A R F$ genes were down-regulated by IAA treatment. In the roots, MtARF8 and MtARF18 were strongly upregulated (more than 10-fold increases) and MtARF1, MtARF9, $M t A R F 10$ and MtARF16 were sharply down-regulated after IAA treatment.

The expression for many of the M. truncatula ARF genes exhibited opposite patterns in shoots versus roots. The expression levels of $10 M t A R F$ genes that were induced by IAA treatment in the shoots were actually down-regulated in the roots and the expression levels of five $M t A R F$ genes were down-regulated in the shoots after IAA treatment, but induced in the roots. The most down-regulated MtARF genes in the roots, MtARF1 and $M t A R F 10$, were all strongly induced in the shoots after IAA treatment [over 10-fold increase, log (expression levels) > 1] (Figure 5). 


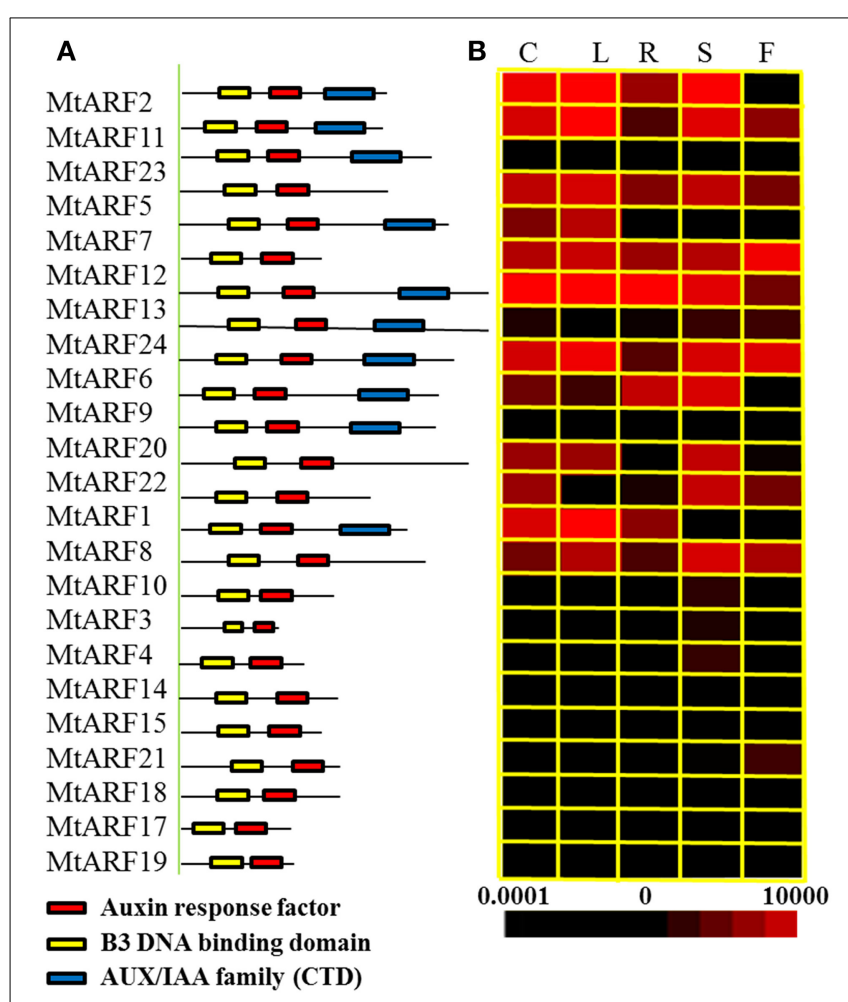

FIGURE 3 | Analysis of protein domains and tissue-specific expression patterns. (A) Depiction of the domain structure of the ARF protein sequences. The auxin response factor domain, B3 DNA binding domain and AUX/IAA family domain are colored in red, yellow, and blue, respectively. (B) Heat map representation for tissue-specific expression patterns of 24MtARF genes. C, cotyledon; L, leaf; $\mathrm{R}$, root; $\mathrm{S}$, shoot; F, flower. Expression patterns of the MtARF genes in five indicated tissues were determined using qRT-PCR. The different colors correspond to the values of the gene expression compare to MtACTIN shown in the bar at the bottom of figure. The color scale of each dendrogram represents expression values; black indicates a low level and red represents a high level of transcript abundance. The expression level of MtACTIN was defined as $1 \times 10^{4}$.

\section{EXPRESSION ANALYSIS OF MTARF GENES DURING THE EARLY PHASE OF S. MELILOTI INFECTION}

To examine change in gene expression of the MtARFs genes during the early stage of rhizobial infection, we compared the MtARF gene expression profiling in the roots and shoots of $S$. melilotiinoculated $M$. truncatula plants with those of mock-inoculated ones over a $72 \mathrm{~h}$ post-inoculation (hpi) period. Many gene expression changes related to the host responses occurred during the pre-infection or initial infection periods (Molesini et al., 2014), so different sampling time points $(6,12,24,48$, and $72 \mathrm{hpi})$ were chosen for gene expression level analysis. 1-NOA that binds to auxin-influx transporters to block auxin polar transport was used to suppress auxin signaling. Mock-inoculated and bacteriainoculated samples were separated into two different groups for both the root and shoot relative RNA level data sets (Figure 6).

Two main patterns for $M t A R F$ gene expressions were observed during the early phase of $S$. melilot $i$ infection. Expression levels of MtARF2, 5, 6, 7, 9, 11, 12, 13, 23, and 24 (Group 1) were similar and were induced during the early phase of $S$. meliloti infection in the shoots and reduced in the roots. The expression levels of MtARF3, 4, 10, 14, 15, 16, 17, 18, 19, and 21 (Group 2) were opposite to genes in Group 1 in that transcript levels of all these genes showed a drastic decline during the early phase of $S$. meliloti infection in the shoots. The duration of the post-infection period after bacteria-inoculation had a particularly significant effect on the expression regulation of MtARF genes in the shoots. From 6 to $72 \mathrm{hpi}$, the changes in gene expressions increased notably in the shoots as the time after inoculation increased. In contrast, the opposite occurred in the roots.

In order to study the effect of $S$. meliloti inoculation on the expressions of MtARF genes, the expressions of MtARF genes were determined with or without $10 \mu \mathrm{M}$ 1-NOA treatment after S. meliloti infection. Our data showed that the changes in MtARF gene expression levels were alleviated by $10 \mu \mathrm{M} 1$-NOA application. With 1-NOA treatment, the expression levels of Group 1 genes were down-regulated and expression levels of Group 2 genes were up-regulated in the shoots compared to the 1-NOA free treatment. In the roots, the 1-NOA treatment induced the expressions of Group 1 genes, but down-regulated the expressions of Group 2 genes compared to the 1-NOA free treatment.

Furthermore, we tested the possible involvement of MtDMI3 (does not cause infections, a M. truncatula gene that is necessary for infection by S. meliloti), a Ca $(2+) /$ calmodulin-dependent protein kinase (CCaMK) that is essential for both arbuscular mycorrhizal (AM) and rhizobial symbioses (Messinese et al., 2007; Chen et al., 2008). In our study, the dmi3 mutant was used to test the expression pattern changes in this infection resistant mutant during the early phase of $S$. meliloti infection. Our data showed that the expression levels of the MtARF genes during S. meliloti infection in the $d m i 3$ mutant were different to the wild-type A17 (Figure 7). The DMI3 mutation reduced the differences in expression responses to $S$. meliloti infection. In contrast to the wild-type A17, it is implied that the dmi3 mutant attenuated auxin signaling and reduced the differences in $S$. meliloti infection responses between the Group 1 genes and the Group 2 genes. The expression levels of Group 1 genes in the $d m i 3$ mutant were down-regulated and the expression levels of Group 2 genes in the dmi3 mutant were increased in the shoots compared to the wildtype A17. In the roots, the DMI3 mutation led to the increases of Group 1 genes and reductions in the expression of Group 2 genes compared to the wild-type A17.

\section{ANALYSIS OF THE AUXIN-RESPONSE cis-ELEMENT IN THE RHIZOBIAL INFECTION RESPONSE GENE PROMOTERS}

Most auxin response gene promoters contain successive auxinresponse elements (AuxRE), which are targeted by auxinresponse factor (ARF) transcription factors at the transcription level (Sakamoto et al., 2013). The AuxRE, some bZIP and MYB transcription factor families are also involved in auxin transcriptional regulation via bZIP Response Elements (ZREs) and Myb Response Elements (MREs) (Berendzen et al., 2012). We examined the promoters of 48 rhizobial-responsive genes for DNA motifs that correlate with auxin regulation (Ortu et al., 2012). Using Ortu's microarray data (2012), 48 rhizobial infection response genes were chosen for promoter auxin-response cis-element analysis. 


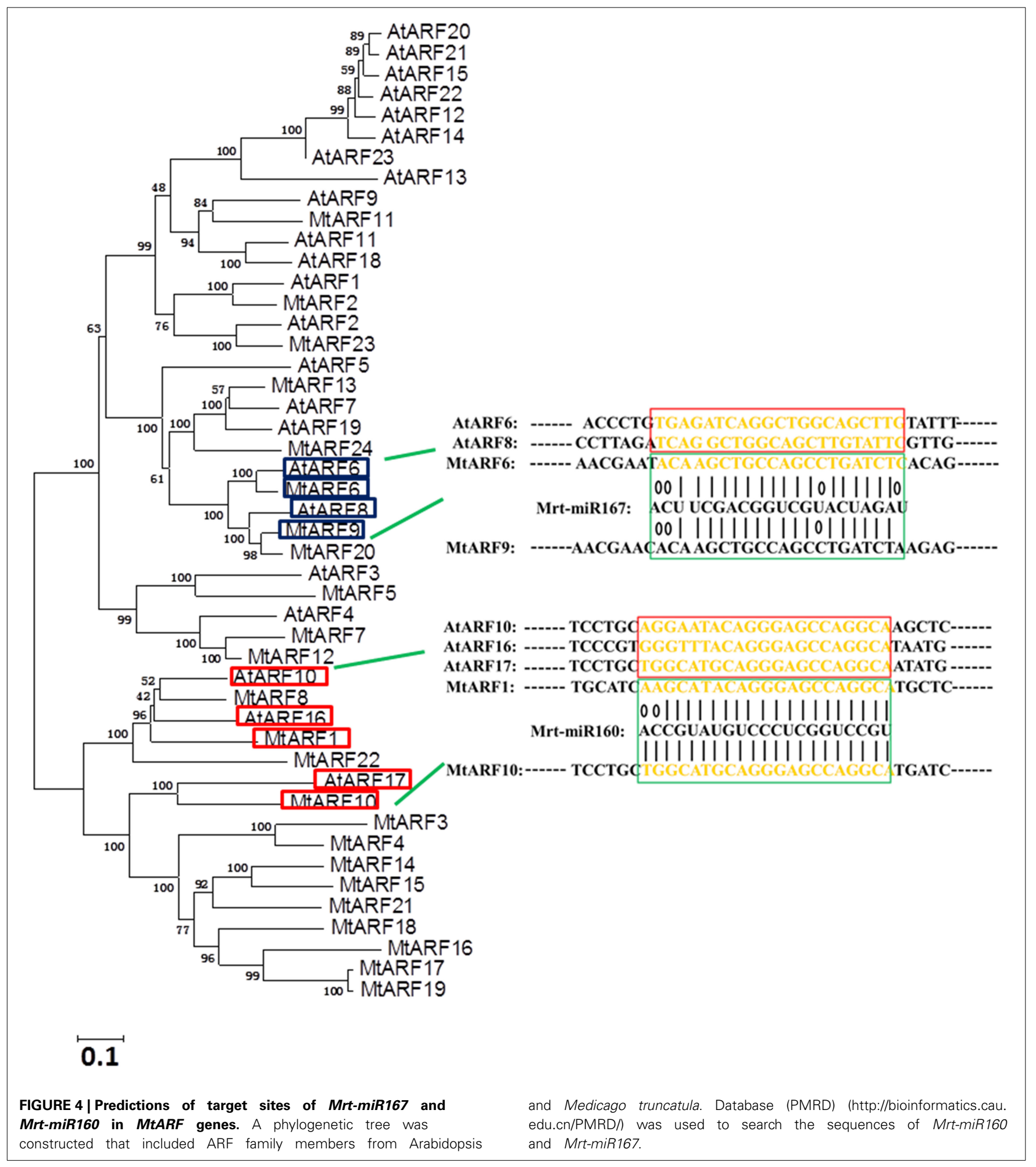

The promoters $(-1000$ to $-1 \mathrm{bp})$ of rhizobial infection response genes were scanned for AUX1 (TGTCTC core sequence), a less stringent variant called AUX2 (TGTVYS), three different ZREs (GRE, TGA, and AC-motif) and two MREs (MRE1: AMCWAMC and MRE2: GGWTW). The motifs for AuxREs,
ZREs, MREs, and MYC2 related elements were more abundant in the promoters of the rhizobial infection response genes (Figure 8). The MRE2 motif was highly frequent at more than twice the levels per $1000 \mathrm{bp}$ promoter region (MRE2: 2.85/1000 bp) as the other genes. GRE, TGA, AC, AUX1, AUX2, 

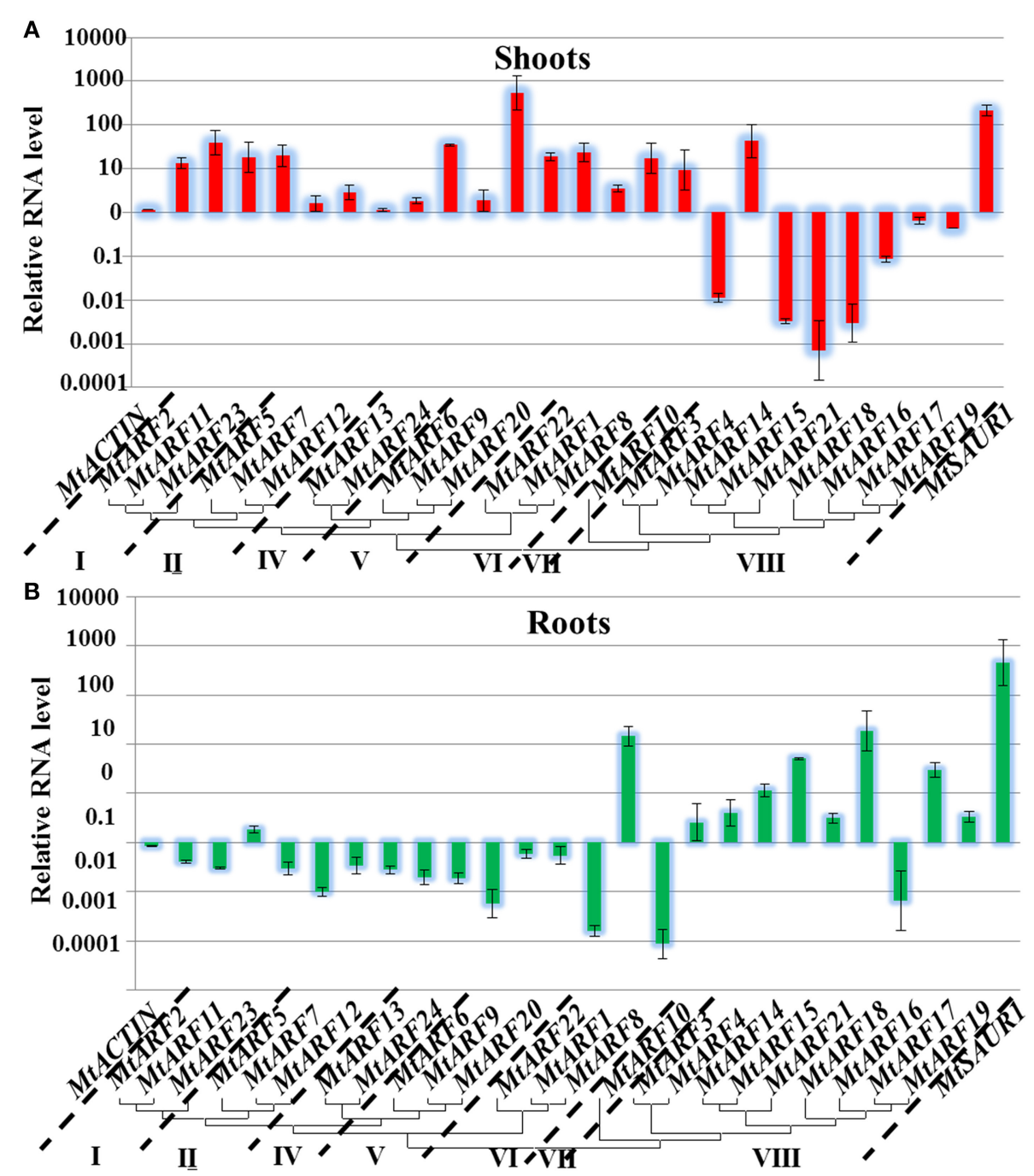

FIGURE 5 | Analysis of MtARF genes expression in response to auxin treatment. Total RNA was extracted from the seedlings shoots (A) and roots (B) tissues of $M$. truncatula for basal expression. The histogram shows the relative expression level of MtARF genes under IAA treatment compared to the mock expression level. The relative mRNA level of individual genes was normalized with respect to the MtACTIN gene. Data from five independent replications were used in the analysis, and standard deviations were shown with error bars. and MRE1 were also present at relatively high levels. These data indicated that many rhizobial infection response genes could be regulated by ARF-mediated auxin signaling.

\section{DISCUSSION}

As an important component of the auxin signaling pathway, ARFs directly bind to and regulate the specific expressions of down-stream target genes during the auxin response process (Cho et al., 2014). Expression and functional characterization of the ARFs are needed if the mechanisms behind how auxin is involved in plant growth and response to environmental stimuli in a spatio-temporal specific manner are to be revealed (Zouine et al., 2014). Auxin has been reported to be an essential regulator of nodulation via regulation of mitosis (van Noorden et al., 2007; Plet et al., 2011). Focusing on the main structural and expression features of $A R F$ genes in M. truncatula, which is a model indeterminate legume, helped us to describe the relationship between ARF-mediated auxin signaling and the symbiotic association with nitrogen-fixing bacteria during the early phase of S. meliloti infection.

\section{CHARACTERIZATION AND ANALYSIS OF THE MIARF GENE FAMILY IN M. TRUNCATULA}

The reference genome sequence of $M$. truncatula, a forage legume with a small genome size ( $\sim 500 \mathrm{Mbp}$ ) (Young et al., 2011), was used to identify the complete MtARF family genes. The number of M. truncatula ARF genes was similar to that in Arabidopsis (23) (Guilfoyle and Hagen, 2007). Domain analyses are consistent with potential roles as ARFs and provided useful clues for predicting their biological functions. The percentage of CTD-truncated MtARFs (54\%) was much higher than the ARF members identified in other plants, such as soybean (15.68\%), Arabidopsis 


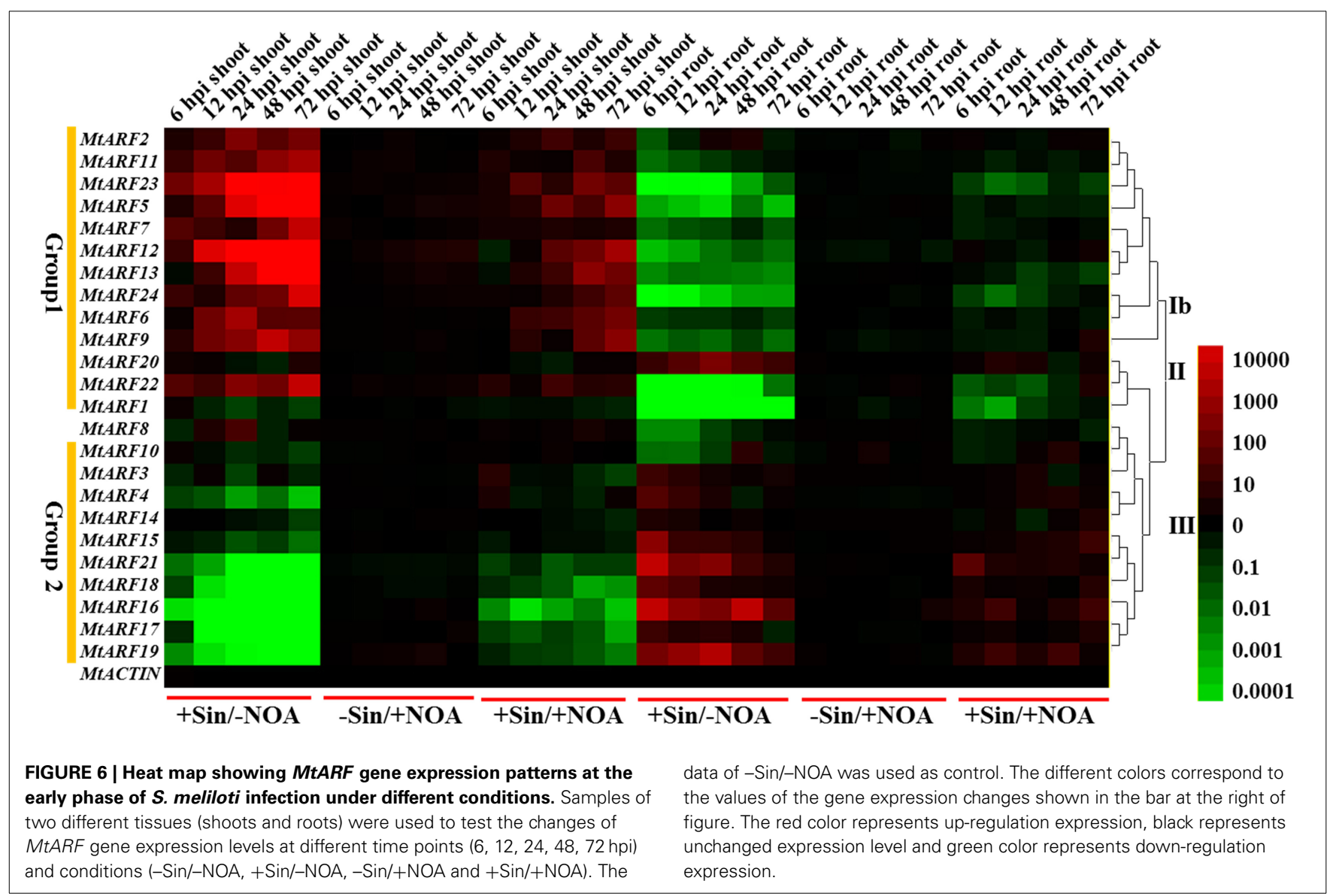

(17.39\%), B. rapa (22.58\%), rice (24\%), and tomato $(28.57 \%)$ (Shen et al., 2010, 2013; Young et al., 2011; Mun et al., 2012). A typical ARF protein contains a conserved N-terminal DNAbinding domain (DBD), a non-conserved MR and a conserved C-terminal dimerization domain (CTD) (Guilfoyle and Hagen, 2007). ARF protein relies on the DBD to bind specifically to auxin response elements (AuxRE: TGTCTC) in the promoters of auxin responsive genes. The CTD, which is involved in homoand hetero-interactions among ARFs, resembles the III and IV domain of Aux/IAA proteins (Ulmasov et al., 1997). The presence of a large number of CTD-truncated MtARFs suggested that many auxin-responsive genes in $M$. truncatula can be regulated in an auxin independent manner. ARF proteins function as transcription activators or repressors and are determined by the amino acid composition of MR (Tiwari et al., 2003). The activator/repressor ratio among ARFs in M. truncatula was only 0.26, which was similar to tomato $(0.27)$ and nearly half of that in Arabidopsis (0.59) or rice (0.56) (Zouine et al., 2014). The data can provide insights into potential functions for MtARF genes in plant developmental regulation and responses to environmental stimulus.

\section{THE CLOSE RELATIONSHIP BETWEEN PHYLOGENETIC ANALYSIS AND THE EXPRESSION PATTERNS OF MtARF GENES}

Previous studies suggested that phylogenetic analysis provided clues on functional prediction of various genes, including transcription factor encoding genes (Fang et al., 2008; Zhang et al., 2008). The close relationship between sequence conservation and expression patterns helps us to select candidate genes that respond to diverse environmental stimuli, including auxin treatment and S. meliloti infection (Wang et al., 2012). Transcript accumulation of most CTD-encoding MtARF genes was higher than the CTD lacking MtARF genes in the cotyledons, leaves, and stems. It suggested that the CTD protein domain may affect the expression levels of the $M t A R F$ genes (Figure 3).

In Arabidopsis, negative regulation of AtARF10 by $m i R 160$ participates in seed germination and post-embryonic developmental programs (Liu et al., 2007). As homologous genes of AtARF10, the expression of MtARF1 and MtARF10 may be also inhibited by $m$ tr-miR160. Recently, $m i R 160$ in leguminous plants soybean has been reported by Turner's group (Turner et al., 2013). A set of ARFs repressor could be silenced in plants overexposing miRNA160, suggesting that auxin hypersensitivity was regulated by miR160 in ARF-dependent manner. Several lines of evidences indicated a role of auxin signaling in nodule development (Bazin et al., 2012). The miR167 also was found to function in ARF-mediated auxin regulation by reinforcing or maintaining transcriptionally established gene expression patterns (Wu et al., 2006).

$M t A R F$ gene expression changes respond rapidly to exogenous auxin treatment. A correlation between phylogenetic analysis and auxin-response expression was also revealed by our studies. Most 


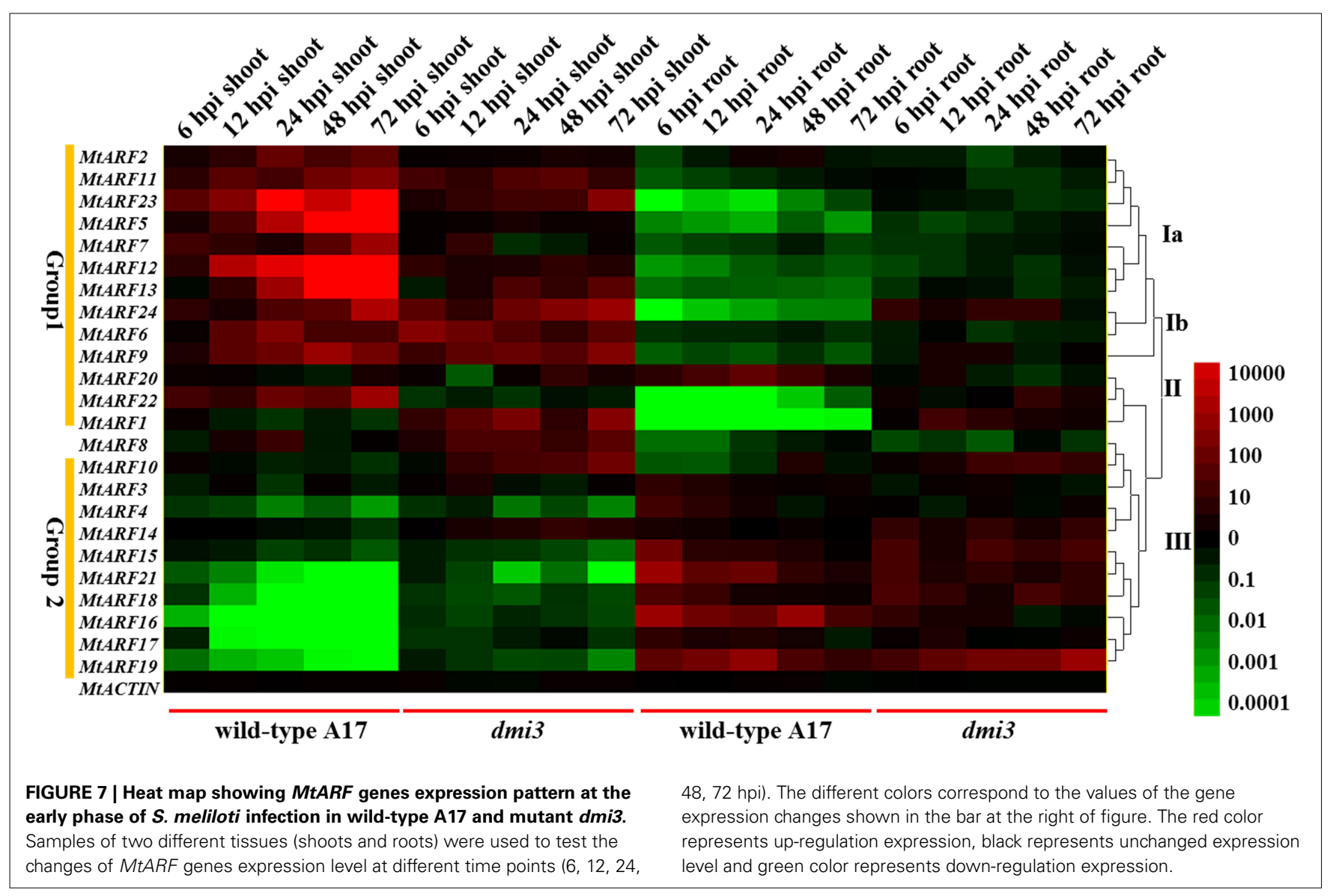

of the MtARF genes that belonged to subfamilies I to VII were induced by IAA treatment in the shoots and were down-regulated in the roots (Figure 5). In contrast, most of the MtARF genes that belonged to subclass VIII were down-regulated by IAA treatment in the shoots, but induced in the roots. All the results showed that there was a close relationship between sequence conservation and the expression patterns of MtARF genes.

\section{THE PUTATIVE FUNCTION OF MTARFs IN NODULE FORMATION DURING THE EARLY PHASE OF S. MELILOTI INFECTION}

Symbiotic interactions between legumes and rhizobia are required for the formation of nitrogen-fixing nodules, which help soil rhizobia convert atmospheric $\mathrm{N}_{2}$ into ammonia for plant absorption (Li et al., 2013). Rhizobial infection and nodule organogenesis are two distinct development processes in nitrogen-fixing nodule formation (Madsen et al., 2010). Many transcriptome and proteome changes occur in both the shoots and roots during the early stage of rhizobial infection, which lead to signal exchanges between the hosts and the bacteria (Godiard et al., 2007; Molesini et al., 2014). A large number of studies have revealed the important roles of auxin in the initiation and development of nodules in different legumes, including white clover, Lotus japonicas and M. truncatula (Mathesius et al., 1998; Pacios-Bras et al., 2003; van Noorden et al., 2006). In our study, we used $M$. truncatula as a model indeterminate legume to investigate how auxin signaling is involved in nodule formation during the early phase of $S$. meliloti infection.

Being essential components of the auxin signaling pathway, ARFs are likely to bind to the down-stream target genes and function as transcriptional mediators, which trigger appropriate physiological responses in a spatio-temporal specific manner. Most MtARFs have been found to be involved in the responses to the $S$. meliloti infection, which suggests a putative role in the formation of nitrogen-fixing nodules. The expression profile of MtARF genes changed significantly during infection and MtARF may activate or suppress the function of many downstream genes involved in the formation of nodules. Among the $24 M t A R F$ genes, only MtARF1 and 8 were expressed inconsistent with a pattern expected for genes involved in the nodulation process. Interestingly, all the MtARFs that contained a CTD domain belonged to Group 1. It indicated that CTD may be involved in ARF-medicated $S$. meliloti infection responses.

Auxin polar transport inhibitors were used to disturb normal auxin transport and auxin signaling. 1-NOA is an important auxin influx polar transport inhibitor that is used widely in plant physiological studies (Parry et al., 2001). We have test several auxin polar transport inhibitors (including NPA, 1-NOA, and TIBA) in our study (data not shown). The data showed that NPA and TIBA displayed severe inhibition on plant roots growth and elongation and 1-NOA did not affect plant roots elongation too much. Therefore, 1-NOA was used to disturb normal 


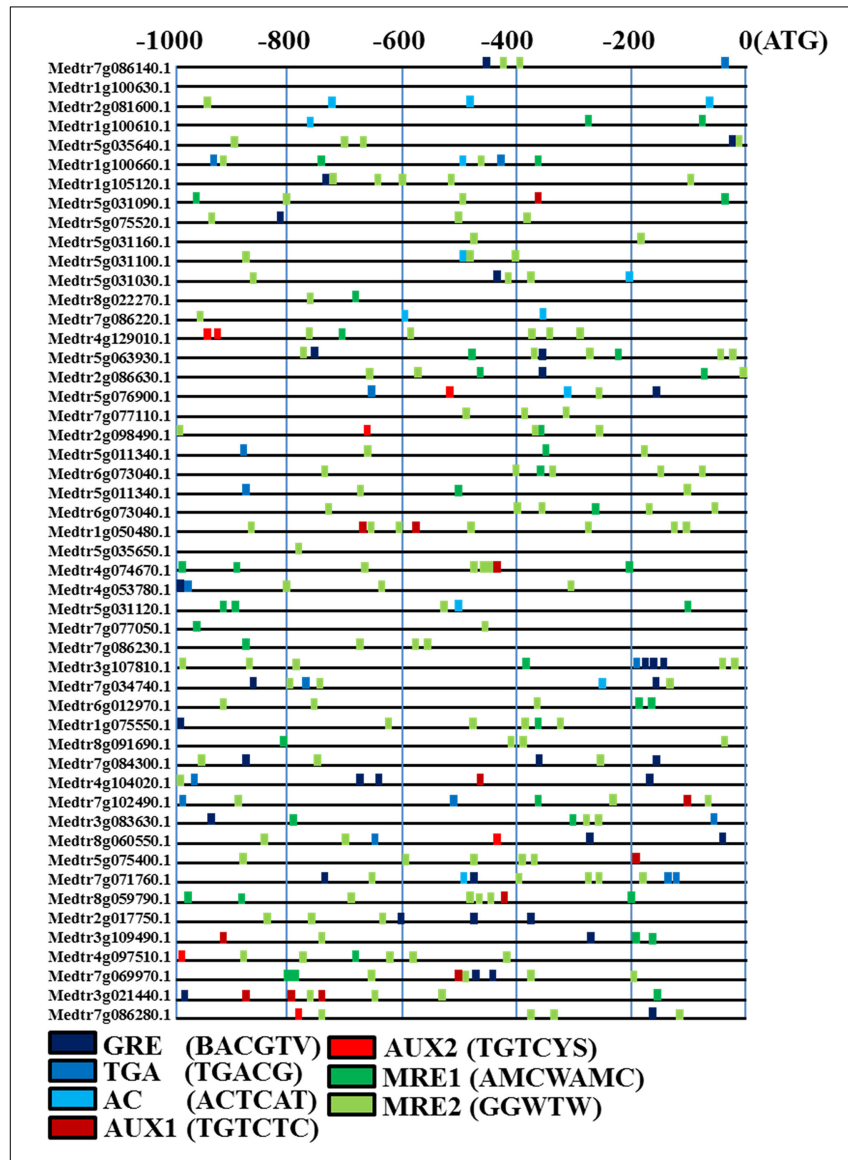

FIGURE 8 | Motif analyses of specific cis-elements in rhizobial infection response gene promoters from $\boldsymbol{M}$. truncatula. The 1000 nucleotides upstream from annotated start codons of differentially expressed were analyzed for the presence of sequences similar to ZRE, AuxRE, and MRE cis-elements, which are given using the presented color code. AUX1 is TGTCTC; AUX2 is TGTVYS, three different ZREs (GRE: BACGTV; TGA: TGACG; AC-motif: ACTCAT) and two MREs (MRE1: AMCWAMC; MRE2: GGWTW).

auxin transport and auxin signaling during the early phase of S. meliloti infection. The inhibition of auxin signaling by 1-NOA changed the expression profiles of $M t A R F$ genes during the early phase of $S$. meliloti infection. Interestingly, there was partial similarity between the expression patterns for MtARF genes in the mutant $d m i 3$ and the expression patterns for the wild-type A17 after the 1-NOA treatment. The data indicated that the infection resistant mutant $d m i 3$ significantly affected the expression of the $M t A R F$ gene family during the early phase of $S$. meliloti infection. However, the expression patterns of MtARF genes under 1-NOA treatment seem to be time (infection)-dependent. In contrast, the expressions of MtARF gene attenuations in dmi3 mutant are less time-dependent, which would be probably due to the insensitivity of the infection. S. meliloti infection may first affect the expression levels of $A R F$ family genes to help nodule formation and differential expressions of MtARF genes may be involved in the resistant phenotype of $d m i 3$ mutant.

M. truncatula is an important model plant for studying symbiosis with nitrogen-fixing bacteria. MtARF gene identification, chromosomal location, protein domain analysis, and expression profiling in response to auxin stimulus in different tissues were all investigated in detail in this study. We have provided the expression profiling of MtARF genes under S. meliloti infection. The involvement of $M t A R F$ gene expression responses to $S$. meliloti infection was an essential process for auxin signaling functioned in the regulation of nodule formation.

\section{ACKNOWLEDGMENTS}

This work was funded by the National Natural Science Foundation of China (31401935 and 31470407), Zhejiang Provincial Natural Science Foundation of China (Grant No. LQ14C060001 and LQ14C020002) and Science and Technology Plan of Zhejiang province (2014C32090). We are grateful to Professor Poovaiah (Washington State University) for the dmi3 mutant and A17 wild type seeds and to Dr. Liqun Du (Hangzhou Normal University) for technical support.

\section{SUPPLEMENTARY MATERIAL}

The Supplementary Material for this article can be found online at: http://www.frontiersin.org/journal/10.3389/fpls.2015.00073/ abstract

\section{REFERENCES}

Aya, K., Hobo, T., Sato-Izawa, K., Ueguchi-Tanaka, M., Kitano, H., and Matsuoka, M. (2014). A novel AP2-type transcription factor, SMALL ORGAN SIZE1, controls organ size downstream of an auxin signaling pathway. Plant Cell Physiol. 55, 897-912. doi: 10.1093/pcp/pcu023

Bazin, J., Bustos-Sanmamed, P., Hartmann, C., Lelandais-Briere, C., and Crespi, M. (2012). Complexity of miRNA-dependent regulation in root symbiosis. Philos. Trans. R. Soc. Lond. B Biol. Sci. 367, 1570-1579. doi: 10.1098/rstb.2011.0228

Berendzen, K. W., Weiste, C., Wanke, D., Kilian, J., Harter, K., and DrogeLaser, W. (2012). Bioinformatic cis-element analyses performed in Arabidopsis and rice disclose bZIP- and MYB-related binding sites as potential AuxREcoupling elements in auxin-mediated transcription. BMC Plant Biol. 12:125. doi: 10.1186/1471-2229-12-125

Blilou, I., Xu, J., Wildwater, M., Willemsen, V., Paponov, I., Friml, J., et al. (2005). The PIN auxin efflux facilitator network controls growth and patterning in Arabidopsis roots. Nature 433, 39-44. doi: 10.1038/nature03184

Bowers, J. E., Chapman, B. A., Rong, J., and Paterson, A. H. (2003). Unravelling angiosperm genome evolution by phylogenetic analysis of chromosomal duplication events. Nature 422, 433-438. doi: 10.1038/nature01521

Chapman, E. J., Greenham, K., Castillejo, C., Sartor, R., Bialy, A., Sun, T. P., et al. (2012). Hypocotyl transcriptome reveals auxin regulation of growth-promoting genes through GA-dependent and -independent pathways. PLoS ONE 7:e36210. doi: 10.1371/journal.pone.0036210

Chen, C., Ane, J. M., and Zhu, H. (2008). OsIPD3, an ortholog of the Medicago truncatula DMI3 interacting protein IPD3, is required for mycorrhizal symbiosis in rice. New Phytol. 180, 311-315. doi: 10.1111/j.1469-8137.2008.02612.x

Cho, H., Ryu, H., Rho, S., Hill, K., Smith, S., Audenaert, D., et al. (2014). A secreted peptide acts on BIN2-mediated phosphorylation of ARFs to potentiate auxin response during lateral root development. Nat. Cell Biol. 16, 66-76. doi: $10.1038 /$ ncb2893

Chung, Y., Maharjan, P. M., Lee, O., Fujioka, S., Jang, S., Kim, B., et al. (2011). Auxin stimulates DWARF4 expression and brassinosteroid biosynthesis in Arabidopsis. Plant J. 66, 564-578. doi: 10.1111/j.1365-313X.2011.04513.x

Engstrom, M., Ehrhardt, W., Mitra, M., and Long, R. (2002). Pharmacological analysis of nod factor-induced calcium spiking in Medicago truncatula. Evidence for the requirement of type IIA calcium pumps and phosphoinositide signaling. Plant Physiol. 128, 1390-1401. doi: 10.1104/pp.010691

Fang, Y., You, J., Xie, K., Xie, W., and Xiong, L. (2008). Systematic sequence analysis and identification of tissue-specific or stress-responsive genes of NAC transcription factor family in rice. Mol. Genet. Genomics 280, 547-563. doi: 10.1007/s00438-008-0386-6 
Godiard, L., Niebel, A., Micheli, F., Gouzy, J., Ott, T., and Gamas, P. (2007). Identification of new potential regulators of the Medicago truncatula-Sinorhizobium meliloti symbiosis using a large-scale suppression subtractive hybridization approach. Mol. Plant Microbe Interact. 20, 321-332. doi: 10.1094/MPMI-20-3-0321

Goetz, M., Vivian-Smith, A., Johnson, S. D., and Koltunow, A. M. (2006). AUXIN RESPONSE FACTOR8 is a negative regulator of fruit initiation in Arabidopsis. Plant Cell 18, 1873-1886. doi: 10.1105/tpc.105.037192

Guilfoyle, T. J., and Hagen, G. (2007). Auxin response factors. Curr. Opin. Plant Biol. 10, 453-460. doi: 10.1016/j.pbi.2007.08.014

Hardtke, C. S., and Berleth, T. (1998). The Arabidopsis gene MONOPTEROS encodes a transcription factor mediating embryo axis formation and vascular development. EMBO J. 17, 1405-1411. doi: 10.1093/emboj/17.5.1405

Harper, R. M., Stowe-Evans, E. L., Luesse, D. R., Muto, H., Tatematsu, K., Watahiki, M. K., et al. (2000). The NPH4 locus encodes the auxin response factor ARF7, a conditional regulator of differential growth in aerial Arabidopsis tissue. Plant Cell 12, 757-770. doi: 10.1105/tpc.12.5.757

Hayashi, K. (2012). The interaction and integration of auxin signaling components. Plant Cell Physiol. 53, 965-975. doi: 10.1093/pcp/pcs035

Kalluri, U. C., Difazio, S. P., Brunner, A. M., and Tuskan, G. A. (2007). Genomewide analysis of $A u x / I A A$ and $A R F$ gene families in Populus trichocarpa. BMC Plant Biol. 7:59. doi: 10.1186/1471-2229-7-59

Kondorosi, E., Redondo-Nieto, M., and Kondorosi, A. (2005). Ubiquitin-mediated proteolysis. To be in the right place at the right moment during nodule development. Plant Physiol. 137, 1197-1204. doi: 10.1104/pp.105.060004

Li, H., Johnson, P., Stepanova, A., Alonso, J. M., and Ecker, J. R. (2004), Convergence of signaling pathways in the control of differential cell growth in Arabidopsis. Dev. Cell 7, 193-204. doi: 10.1016/j.devcel.2004.07.002

Li, X., Lei, M., Yan, Z., Wang, Q., Chen, A., Sun, J., et al. (2013). The REL3mediated TAS3 ta-siRNA pathway integrates auxin and ethylene signaling to regulate nodulation in Lotus japonicus. New Phytol. 201, 531-544. doi: $10.1111 / \mathrm{nph} .12550$

Liu, P. P., Montgomery, T. A., Fahlgren, N., Kasschau, K. D., Nonogaki, H., and Carrington, J. C. (2007). Repression of AUXIN RESPONSE FACTOR10 by microRNA160 is critical for seed germination and post-germination stages. Plant J. 52, 133-146. doi: 10.1111/j.1365-313X.2007.03218.x

Madsen, L. H., Tirichine, L., Jurkiewicz, A., Sullivan, J. T., Heckmann, A. B., Bek, A. S., et al. (2010). The molecular network governing nodule organogenesis and infection in the model legume Lotus japonicus. Nat. Commun. 1, 10. doi: $10.1038 /$ ncomms 1009

Mathesius, U., Schlaman, H. R., Spaink, H. P., Of Sautter, C., Rolfe, B. G., and Djordjevic, M. A. (1998). Auxin transport inhibition precedes root nodule formation in white clover roots and is regulated by flavonoids and derivatives of chitin oligosaccharides. Plant J. 14, 23-34. doi: 10.1046/j.1365313X.1998.00090.X

Messinese, E., Mun, J. H., Yeun, L. H., Jayaraman, D., Rouge, P., Barre, A., et al. (2007). A novel nuclear protein interacts with the symbiotic DMI3 calciumand calmodulin-dependent protein kinase of Medicago truncatula. Mol. Plant Microbe Interact. 20, 912-921. doi: 10.1094/MPMI-20-8-0912

Molesini, B., Cecconi, D., Pii, Y., and Pandolfini, T. (2014). Local and systemic proteomic changes in Medicago truncatula at an early phase of Sinorhizobium meliloti infection. J. Proteome Res. 13, 408-421. doi: 10.1021/ pr4009942

Mun, J. H., Yu, H. J., Shin, J. Y., Oh, M., Hwang, H. J., and Chung, H. (2012). Auxin response factor gene family in Brassica rapa: genomic organization, divergence, expression, and evolution. Mol. Genet. Genomics 287, 765-784. doi: 10.1007/s00438-012-0718-4

Nallu, S., Silverstein, K. A., Samac, D. A., Bucciarelli, B., Vance, C. P., and VandenBosch, K. A. (2013). Regulatory patterns of a large family of defensinlike genes expressed in nodules of Medicago truncatula. PLoS ONE 8:e60355. doi: 10.1371/journal.pone. 0060355

Narise, T., Kobayashi, K., Baba, S., Shimojima, M., Masuda, S., Fukaki, H., et al. (2010). Involvement of auxin signaling mediated by IAA14 and ARF7/19 in membrane lipid remodeling during phosphate starvation. Plant Mol. Biol. 72, 533-544. doi: 10.1007/s11103-009-9589-4

Nishimura, T., Wada, T., Yamamoto, K. T., and Okada, K. (2005). The Arabidopsis STV1 protein, responsible for translation reinitiation, is required for auxin-mediated gynoecium patterning. Plant Cell 17, 2940-2953. doi: $10.1105 /$ tpc. 105.036533
Ortu, G., Balestrini, R., Pereira, A., Becker, D., Kuster, H., and Bonfante, P. (2012). Plant genes related to gibberellin biosynthesis and signaling are differentially regulated during the early stages of AM fungal interactions. Mol. Plant 5, 951-954. doi: $10.1093 / \mathrm{mp} / \mathrm{sss} 027$

Pacios-Bras, C., Schlaman, H. R., Boot, K., Admiraal, P., Langerak, J. M., Stougaard, J., et al. (2003). Auxin distribution in Lotus japonicus during root nodule development. Plant Mol. Biol. 52, 1169-1180. doi: 10.1023/B:PLAN.0000004308.78057.f5

Parry, G., Delbarre, A., Marchant, A., Swarup, R., Napier, R., Perrot-Rechenmann, C., et al. (2001). Novel auxin transport inhibitors phenocopy the auxin influx carrier mutation aux1. Plant J. 25, 399-406. doi: 10.1046/j.1365313x.2001.00970.x

Plet, J., Wasson, A., Ariel, F., Le Signor, C., Baker, D., Mathesius, U., et al. (2011). MtCRE1-dependent cytokinin signaling integrates bacterial and plant cues to coordinate symbiotic nodule organogenesis in Medicago truncatula. Plant J. 65, 622-633. doi: 10.1111/j.1365-313X.2010.04447.x

Qi, Y., Wang, S., Shen, C., Zhang, S., Chen, Y., Xu, Y., et al. (2012). OsARF12, a transcription activator on auxin response gene, regulates root elongation and affects iron accumulation in rice (Oryza sativa). New Phytol. 193, 109-120. doi: 10.1111/j.1469-8137.2011.03910.x

Rightmyer, A. P., and Long, S. R. (2011). Pseudonodule formation by wild-type and symbiotic mutant Medicago truncatula in response to auxin transport inhibitors. Mol. Plant Microbe Interact. 24, 1372-1384. doi: 10.1094/MPMI-0411-0103

Roudier, F., Fedorova, E., Lebris, M., Lecomte, P., Gyorgyey, J., Vaubert, D., et al. (2003). The Medicago species A2-type cyclin is auxin regulated and involved in meristem formation but dispensable for endoreduplication-associated developmental programs. Plant Physiol. 131, 1091-1103. doi: 10.1104/pp.102.011122

Sakamoto, T., Morinaka, Y., Inukai, Y., Kitano, H., and Fujioka, S. (2013). Auxin signal transcription factor regulates expression of the brassinosteroid receptor gene in rice. Plant J. 73, 676-688. doi: 10.1111/tpj.12071

Shen, C., Wang, S., Bai, Y., Wu, Y., Zhang, S., Chen, M., et al. (2010). Functional analysis of the structural domain of ARF proteins in rice (Oryza sativa L.). J. Exp. Bot. 61, 3971-3981. doi: 10.1093/jxb/erq208

Shen, C., Wang, S., Zhang, S., Xu, Y., Qian, Q., Qi, Y., et al. (2013). OsARF16, a transcription factor, is required for auxin and phosphate starvation response in rice (Oryza sativa L.). Plant Cell Environ. 36, 607-620. doi: 10.1111/pce.12001

Tan, X., Calderon-Villalobos, L. I., Sharon, M., Zheng, C., Robinson, C. V., Estelle, M., et al. (2007). Mechanism of auxin perception by the TIR1 ubiquitin ligase. Nature 446, 640-645. doi: 10.1038/nature05731

Tiwari, S. B., Hagen, G., and Guilfoyle, T. (2003). The roles of auxin response factor domains in auxin-responsive transcription. Plant Cell 15, 533-543. doi: $10.1105 /$ tpc.008417

Turner, M., Nizampatnam, N. R., Baron, M., Coppin, S., Damodaran, S., Adhikari, S., et al. (2013). Ectopic expression of miR160 results in auxin hypersensitivity, cytokinin hyposensitivity, and inhibition of symbiotic nodule development in soybean. Plant Physiol. 162, 2042-2055. doi: 10.1104/pp.113.220699

Ulmasov, T., Hagen, G., and Guilfoyle, T. J. (1997). ARF1, a transcription factor that binds to auxin response elements. Science 276, 1865-1868. doi: 10.1126/science.276.5320.1865

van Noorden, G. E., Kerim, T., Goffard, N., Wiblin, R., Pellerone, F. I., Rolfe, B. G., et al. (2007). Overlap of proteome changes in Medicago truncatula in response to auxin and Sinorhizobium meliloti. Plant Physiol. 144, 1115-1131. doi: $10.1104 /$ pp.107.099978

van Noorden, G. E., Ross, J. J., Reid, J. B., Rolfe, B. G., and Mathesius, U. (2006). Defective long-distance auxin transport regulation in the Medicago truncatula super numeric nodules mutant. Plant Physiol. 140, 1494-1506. doi: 10.1104/pp.105.075879

Wang, D., Pei, K., Fu, Y., Sun, Z., Li, S., Liu, H., et al. (2007). Genome-wide analysis of the auxin response factors (ARF) gene family in rice (Oryza sativa). Gene 394, 13-24. doi: 10.1016/j.gene.2007.01.006

Wang, Y., Deng, D., Shi, Y., Miao, N., Bian, Y., and Yin, Z. (2012). Diversification, phylogeny and evolution of auxin response factor (ARF) family: insights gained from analyzing maize ARF genes. Mol. Biol. Rep. 39, 2401-2415. doi: 10.1007/s11033-011-0991-z

Wasson, A. P., Pellerone, F. I., and Mathesius, U. (2006). Silencing the flavonoid pathway in Medicago truncatula inhibits root nodule formation and prevents auxin transport regulation by rhizobia. Plant Cell 18, 1617-1629. doi: $10.1105 /$ tpc. 105.038232 
Wu, M. F., Tian, Q., and Reed, J. W. (2006). Arabidopsis microRNA167 controls patterns of ARF6 and ARF8 expression, and regulates both female and male reproduction. Development 133, 4211-4218. doi: 10.1242/dev.02602

Yang, J. H., Han, S. J., Yoon, E. K., and Lee, W. S. (2006). Evidence of an auxin signal pathway, microRNA167-ARF8-GH3, and its response to exogenous auxin in cultured rice cells. Nucleic Acids Res. 34, 1892-1899. doi: 10.1093/nar/ gkl118

Young, N. D., Debelle, F., Oldroyd, G. E., Geurts, R., Cannon, S. B., Udvardi, M. K., et al. (2011). The Medicago genome provides insight into the evolution of rhizobial symbioses. Nature 480, 520-524. doi: 10.1038/nature10625

Zhang, G., Chen, M., Chen, X., Xu, Z., Guan, S., Li, L. C., et al. (2008). Phylogeny, gene structures, and expression patterns of the ERF gene family in soybean (Glycine max L.). J. Exp. Bot. 59, 4095-4107. doi: 10.1093/jxb/ern248

Zouine, M., Fu, Y., Chateigner-Boutin, A. L., Mila, I., Frasse, P., Wang, H., et al. (2014). Characterization of the tomato $A R F$ gene family uncovers a multilevels post-transcriptional regulation including alternative splicing. PLoS ONE 9:e84203. doi: 10.1371/journal.pone.0084203
Conflict of Interest Statement: The authors declare that the research was conducted in the absence of any commercial or financial relationships that could be construed as a potential conflict of interest.

Received: 14 November 2014; accepted: 27 January 2015; published online: 24 February 2015.

Citation: Shen C, Yue R, Sun T, Zhang L, Xu L, Tie S, Wang H and Yang Y (2015) Genome-wide identification and expression analysis of auxin response factor gene family in Medicago truncatula. Front. Plant Sci. 6:73. doi: 10.3389/fpls.2015.00073

This article was submitted to Plant-Microbe Interaction, a section of the journal Frontiers in Plant Science.

Copyright (C) 2015 Shen, Yue, Sun, Zhang, Xu, Tie, Wang and Yang. This is an openaccess article distributed under the terms of the Creative Commons Attribution License (CC BY). The use, distribution or reproduction in other forums is permitted, provided the original author(s) or licensor are credited and that the original publication in this journal is cited, in accordance with accepted academic practice. No use, distribution or reproduction is permitted which does not comply with these terms. 